\title{
AN ARTIFICIAL NEURAL NETWORK APPROACH TO SINKHOLE HAZARD ASSESSMENT FOR EAST CENTRAL FLORIDA
}

\author{
Yong Je Kim \\ Department of Civil, Environmental, and Construction Engineering, University of Central Florida \\ 4000 Central Florida Blvd \\ Orlando,FL 32816,USA,yongkim@knights.ucf.edu
}

\author{
Boo Hyun Nam \\ Department of Civil, Environmental, and Construction Engineering, University of Central Florida \\ 4000 Central Florida Blvd \\ Orlando,FL 32816,USA, boohyun.nam@ucf.edu
}

\section{Qipeng Phil Zheng}

Department of Industrial Engineering and Management Systems, University of Central Florida

4000 Central Florida Blvd

Orlando, FL 32816, USA, qipeng.zheng@ucf.edu

\begin{abstract}
The state of Florida sits on the karst terrain where soluble bedrocks are underlain; thus, a sinkhole is a common geohazard. These sinkholes have caused damage to property and infrastructure, as well as threatened human life. It is essential to develop a tool for predicting the potential of sinkhole occurrence. This study presents the methodology of the development of the sinkhole hazard model and map. An artificial neural network (ANN) method was employed. A sinkhole inventory map was prepared using Subsidence Incident Reports of Florida Geological Survey (FGS) with GIS. Hydrogeological factors related to soil erosion and stability (or ground collapse) were identified and used in model development. The selected seven contributing factors include hydraulic head difference, groundwater recharge rate, soil permeability, overburden thickness, surficial aquifer system thickness, intermediate aquifer system thickness, and proximity to karst features. The results show that the Orlando area has a higher probability of larger sinkholes than the Ocala area. This result is consistent with the fact that areas with thick overburden layers create larger sinkholes than thin areas.
\end{abstract}

\section{Introduction}

Sinkholes are a common geohazard in karst areas where soluble bedrock is underlain. Stories about sinkholerelated incidents often make headlines in the news, and the sinkholes can cause heavy losses to property and in- frastructure. On average, sinkholes result in more than $\$ 300$ million in damage each year in the United States, and this estimate is likely to increase as the U.S. population and related developments continue to grow (Kuniansky et al., 2016; Weary, 2015). In Florida, sinkhole claims surged from 2,360 to 6,694 between 2006 and 2010, totaling 24,671 claims at an approximate cost of $\$ 1.4$ billion according to the report by the Florida Office of Insurance Regulation (Florida Office of Insurance Regulation, 2010).

To ensure stable land use and development in karst regions, it is critical to develop the regional management and prevention plans for sinkholes. Sinkhole susceptibility mapping is one of the most important steps to minimize or mitigate the damages associated with sinkholes by predicting the sinkhole prone areas in advance. Various methodologies and techniques have been proposed for producing sinkhole susceptibility maps. They are generally grouped into two: qualitative and quantitative approaches (Gutiérrez et al., 2008; Zhou et al., 2016). The qualitative method is subjective, based on expert knowledge, and demonstrate the hazard levels in descriptive terms. The quantitative method, on the other hand, is objective which estimates the likelihood (or probability) of sinkhole occurrence in the area based on numerical expressions of the relationship between the distribution of sinkholes and contributing factors (Kim and Nam, 2018; Kim and Nam, 2017; Ozdemir, 2016; Subedi et 
al., 2019). Nowadays, conventional qualitative methods have been gradually losing popularity and frequency in use due to the less reliable and subjective nature.

Sinkhole susceptibility maps are useful for planners and engineers to make well-informed decisions in the management and mitigation of sinkhole hazards. Traditional sinkhole susceptibility maps only provide location-related information, not the size information. Since the level of damage varies depending on the size of the sinkhole, it is important to consider the sinkhole size information for accurate sinkhole hazard assessment. In addition, if the sinkhole size can be estimated, proper remedial measures can be taken for the degree of damage and the excessive loss can be minimized.

The main objective of this study is to construct a methodology to develop the sinkhole location-size model. In order to achieve this goal, there are difficulties in the existing hazard mapping methods and techniques because sinkhole-contributing factors are either statistically dependent or independent. Therefore, an ANN method was used and could integrate the location and size of the sinkhole occurrence.

\section{Study Area}

The East Central Florida (ECF) region was selected as the study area in this paper. Geographically, this area lies within latitude from $29^{\circ} 25^{\prime} \mathrm{N}$ to $27^{\circ} 50^{\prime} \mathrm{N}$ and longitude from $82^{\circ} 35^{\prime} \mathrm{W}$ to $80^{\circ} 30^{\prime} \mathrm{W}$ and covers an area of about $22,000 \mathrm{~km}^{2}$ (see Figure 1). Topographically, the ECF region has a generally flat land surface ranging in altitude from 0 to $94 \mathrm{~m}$ above mean sea level. Geologically, the main lithology in the area includes marine limestone, dolomite, shale, sand, and anhydrite (Lichtler, 1972; Tibbals, 1990). ECF is under subtropical climate with repeated wet and dry seasons. The average annual rainfall is $1,350 \mathrm{~mm}$. The wet season normally is from June to September and the dry season is from October to May. The mean monthly rainfall dramatically increases from $84 \mathrm{~mm}$ in May to $222 \mathrm{~mm}$ in June and decreases from $153 \mathrm{~mm}$ in September to $84 \mathrm{~mm}$ in October. The lithologic sequence underlying ECF is generally divided into three hydrogeologic units based on hydrologic characteristics of the formations. From top to bottom, the hydrogeologic units are (1) surficial aquifer, (2) intermediate aquifer or, if these rocks have no water-supply potential, intermediate confining unit; and (3) Upper Floridan aquifer system (Hickey and Vecchioli, 1986; Lee et al., 1991). The surficial aquifer system (SAS) is predomi-

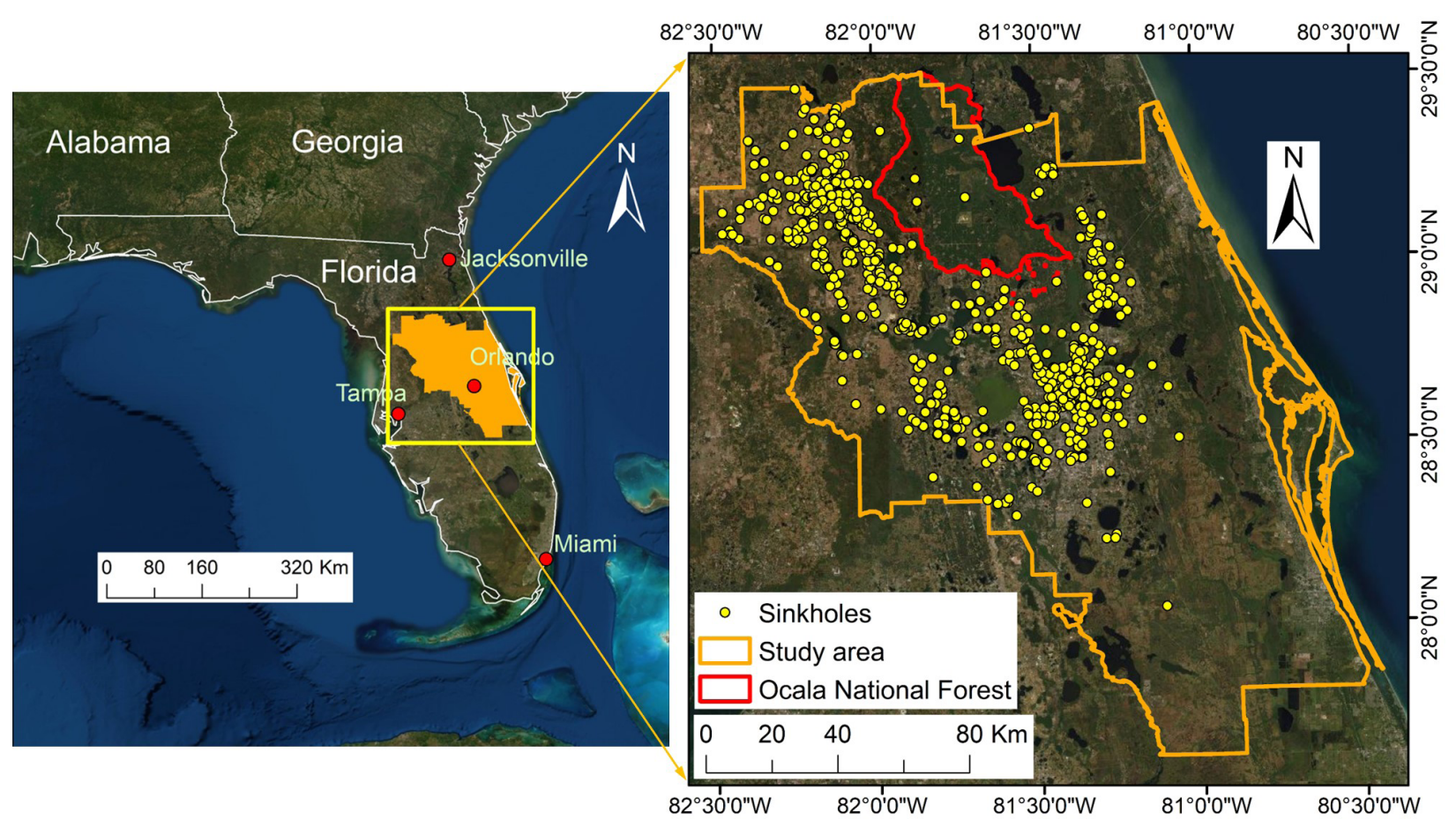

Figure 1. Location of the study area and sinkhole inventory. 
nantly sand, the intermediate aquifer system (IAS) is interbedded siliciclastics and carbonates, and the Floridan aquifer system (FAS) is massive carbonates (Tihansky and Knochenmus, 2001). In ECF, unconsolidated overburden comprised of layers of surficial and intermediate aquifer sediments covers the carbonate bedrock, mainly limestone and dolostone.

The northwestern area of ECF is characterized by extensive karst features, while rarely found in areas further south and along the east coast. The northern area has a thin overburden soil layer as opposed to the southern area that has a relatively thicker overburden soil layer (up to $100 \mathrm{~m}$ ) overlying bedrock. In addition, the east coast generally has lower hydraulic head difference and groundwater recharge rate than the inland areas. Geologically, the overburden soils of the east coastal area contain more fine-grained carbonate and less clay, which leads to very limited karst (Upchurch et al., 2019). These hydrogeological characteristics of ECF are closely related to the distribution of sinkholes.

\section{Data Preparation}

The sinkhole database of this study comprises a sinkhole inventory map and seven sinkhole contributing factors as input variables, namely hydraulic head difference, groundwater recharge rate, soil permeability, overburden thickness, SAS thickness, IAS thickness, and proximity to karst features. In this study, the sinkhole inventory map was prepared by using the Subsidence Incident Report (SIR) database. In ECF, a total of 1,051 sinkholes have been reported since the 1950s (FDEP, 2019). The SIR database contains information about the location and size of the sinkholes.

It is important to note that the spatial distribution of reported sinkhole locations is highly dependent on population size since most SIR databases are based on purely voluntary reports. In fact, 75\% (786) of the reported sinkholes were found in areas with high population densities (more than 100 people $/ \mathrm{km}^{2}$ ), which covers only $25 \%$ of the study area. Despite sinkhole favorable hydrogeological conditions (i.e. high hydraulic head difference and groundwater recharge rate) in the Ocala National Forest, a noticeable decline of sinkhole density is observed, which may be due to underreported sinkholes (see Figure 1).
All layers of sinkhole contributing factors were collected from state and federal agencies as well as other digital GIS databases (e.g. St. Johns River Water Management District, U.S. Geological Survey, and FGS), and processed in ArcGIS with a grid size of $500 \mathrm{~m} \times 500 \mathrm{~m}$.

\section{Sinkhole Contributing Factors}

In order to verify the selection of contributing factors, the relationship between the sinkhole density and sinkhole contributing factors in the study area was evaluated. In this process, factors that are not correlated with sinkhole occurrence can be identified and removed before modeling. 550 sinkholes (70\%) were randomly selected and analyzed for this purpose. Figure 2 shows the correlation between sinkhole density (per square kilometer) and seven contributing factors. As seen in the figure, the sinkhole densities in ECF generally either increase or decrease with increasing the value of the contributing factor. These sinkhole density patterns confirm that all seven contributing factors selected correlate with the development of the sinkhole, which can be considered as input variables for the sinkhole hazard model.

As the value of factors related to soil erosion such as head difference, recharge rate, and soil permeability increase, the density of sinkholes also increases. It can be seen that sinkholes are rarely developed in areas with a low head difference, recharge rate, and soil permeability. And, as a result of the factors related to stability, excessive increase in overburden thickness as well as both SAS and IAS thicknesses, generally decreases sinkhole density. In addition, as the proximity to karst features increases, the sinkhole density tends to decrease.

The correlation between the seven factors was also determined by Spearman's correlation test and the results are shown in Table 1 (Corder and Foreman, 2009). As a result, it was confirmed that the factors are closely related to each other and that a factor such as proximity to karst features has a significant correlation with all six other factors. Overburden thickness, for example, was positively correlated with SAS and IAS thicknesses and proximity to karst features, and negatively correlated with head difference and recharge rate. 

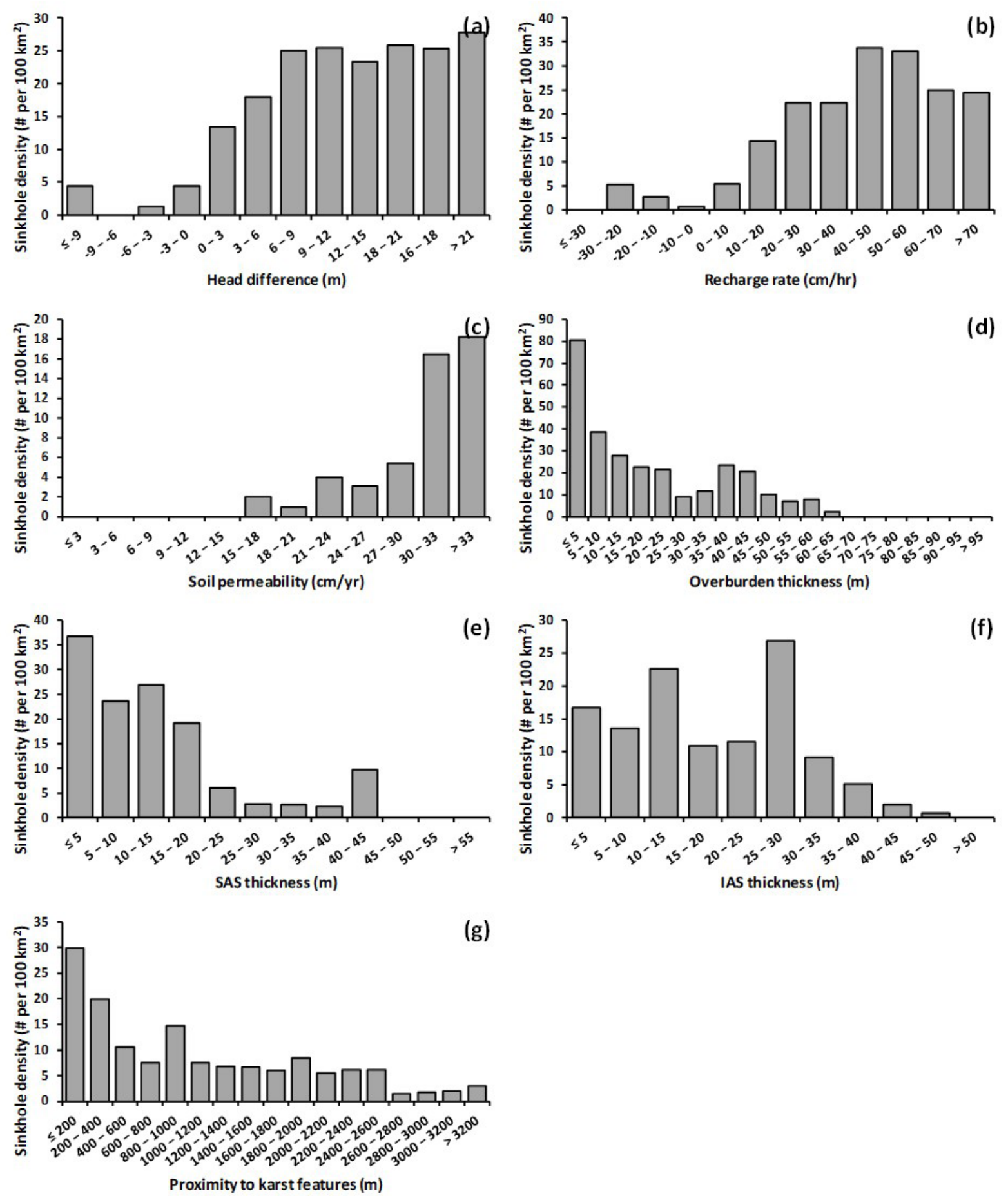

Figure 2. Correlation between sinkhole density and contributing factors: (a) head difference, (b) recharge rate, (c) soil permeability, (d) overburden thickness, (e) SAS thickness, (f) IAS thickness, and (g) proximity to karst features. 


\section{Methodology}

The workflow used in this study is shown in Figure 3. In the first step, the sinkhole inventory map and layers of sinkhole contributing factors were prepared. In the second step, the correlation of the sinkhole contributing factors to sinkhole occurrence was checked to ensure the selected factors are used as input to the model. In the third step, the sinkhole location-size model was developed using an artificial neural network (ANN) technique. In the fourth step, categories of sinkhole sizes were defined. A total of ten size categories were set at 3-meter intervals. Category 1 is no sinkhole, Category 2 is a size of 0 to 3 $\mathrm{m}$, Category 3 is a size of 3 to $6 \mathrm{~m}$, and so on. Category 10 is a size greater than $24 \mathrm{~m}$. For any sinkhole data that have no size information, the Markov chain Monte Carlo (MCMC) method was used to impute the missing values. In this process, various statistical analysis methods such as Box-Cox transformation, Grubbs' outlier test, and
Spearman's rho correlation were used (Smith, 2018). In the fifth step, the ANN method was applied to assess the sinkhole hazard, and then the sinkhole hazard map was produced.

ANN is a nonlinear computational method that was inspired by the biological interaction in the neural system (Zou et al., 2009). It consists of numerous interconnected processing elements (neurons) that work simultaneously to solve a specific problem. By default, the neural network consists of an input layer, one or more hidden layers, and an output layer. All inputs are fed to the model through the input layer, and hidden (process) layers are used to process the inputs received from the input layers. After processing, the data is available in the output layer. The structure of the ANN model in this study is illustrated in Figure 4.

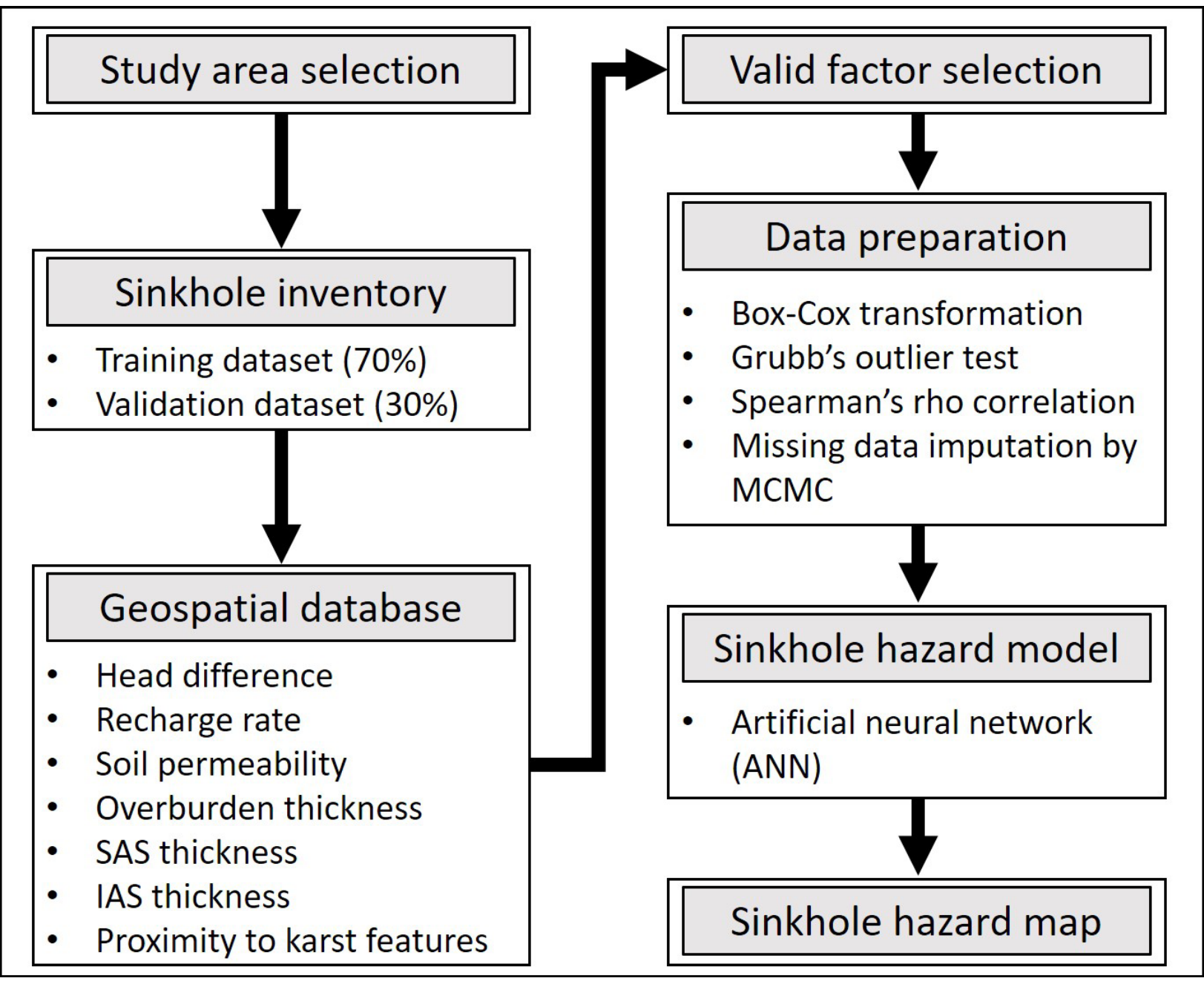

Figure 3. The workflow of the location-size sinkhole hazard analysis. 


\begin{tabular}{|c|c|c|c|c|c|c|c|}
\hline Variables & $\begin{array}{l}\text { Head } \\
\text { difference } \\
{[h]} \\
(\mathrm{m}) \\
\end{array}$ & $\begin{array}{l}\text { Recharge } \\
\text { rate }[R] \\
(\mathrm{cm} / \mathrm{yr})\end{array}$ & $\begin{array}{l}\text { Soil } \\
\text { permeability } \\
{[k]} \\
(\mathrm{cm} / \mathrm{hr})\end{array}$ & $\begin{array}{l}\text { Overburden } \\
\text { thickness }\left[t_{o}\right] \\
\text { (m) }\end{array}$ & $\begin{array}{l}\text { SAS } \\
\text { thickness } \\
{\left[t_{s}\right]} \\
(\mathrm{m})\end{array}$ & $\begin{array}{l}\text { IAS } \\
\text { thickness } \\
{\left[t_{i}\right]} \\
(\mathrm{m})\end{array}$ & $\begin{array}{l}\text { Proximity } \\
\text { to karst } \\
\text { features }[d] \\
\text { (m) }\end{array}$ \\
\hline$h(\mathrm{~m})$ & 1 & 0.341 & -0.183 & -0.072 & 0.048 & -0.173 & 0.250 \\
\hline$R(\mathrm{~cm} / \mathrm{yr})$ & 0.341 & 1 & -0.035 & -0.299 & -0.207 & -0.327 & -0.173 \\
\hline$k(\mathrm{~cm} / \mathrm{hr})$ & -0.183 & -0.035 & 1 & 0.010 & 0.030 & -0.008 & -0.086 \\
\hline$t_{0}(\mathrm{~m})$ & -0.072 & -0.299 & 0.010 & 1 & 0.744 & 0.825 & 0.581 \\
\hline$t_{s}(\mathrm{~m})$ & 0.048 & -0.207 & 0.030 & 0.744 & 1 & 0.306 & 0.483 \\
\hline$t_{i}(\mathrm{~m})$ & -0.173 & -0.327 & -0.008 & 0.825 & 0.306 & 1 & 0.449 \\
\hline$d(\mathrm{~m})$ & 0.250 & -0.173 & -0.086 & 0.581 & 0.483 & 0.449 & 1 \\
\hline
\end{tabular}

Table 1. Correlation matrix by Spearman's correlation test.

(Note: Values in bold are different from 0 with a significance level alpha=0.05.)

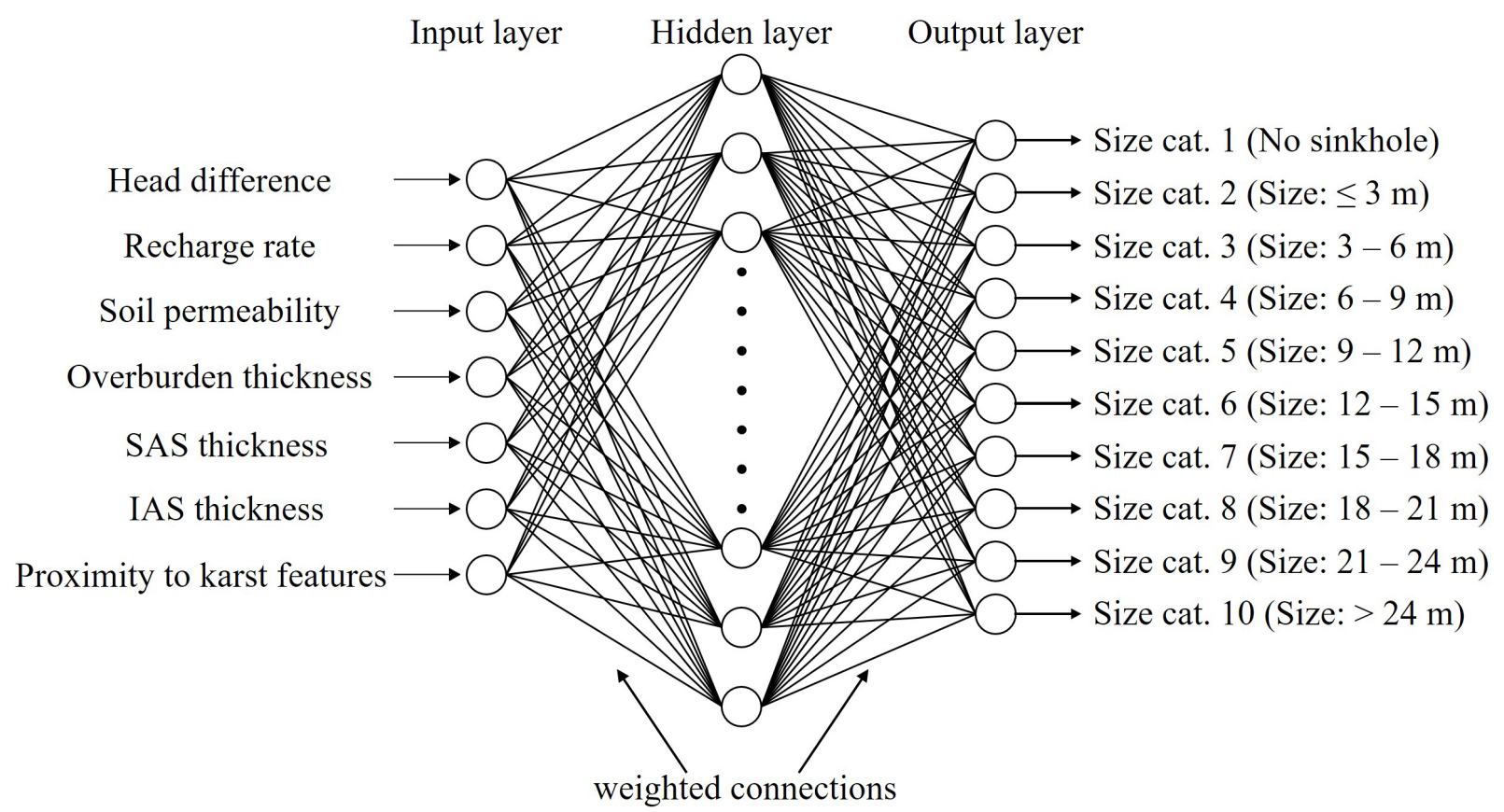

Figure 4. Structure of the ANN model.

The backpropagation algorithm is the most commonly used algorithm for training ANN. It repeats a cycle, including signal propagation and weight updates. The signals in the data are propagated forward throughout the network, layer by layer, and then the loss function is used to compare the result with the expected output. The error propagates backward through the network from the output layer to the input layer and adjusts the weights and thresholds of each neuron based on the associated error value.
The learning rate is usually the most important hyperparameter for tuning neural networks and affects model performance (Wu et al., 2019). In this study, the learning rate is calculated by Equation 1 where $\eta(n)$ is the learning rate in the $n$-th times training, $\eta_{\min }$ and $\eta_{\max }$ are the minimum and maximum value of the learning rate, respectively, and $d$ is the delay rate.

$$
\eta(n)=\eta(n-1) \times \exp \left[\log \left(\eta_{\min } / \eta_{\max }\right) / d\right]
$$

\section{Equation 1}


In this study, the ANN model consists of an input layer, one hidden (process) layer, and one output layer. Each neuron in the input layer represents seven sinkhole contributing factors, while ten output neurons represent different categories of sinkhole sizes at 3-meter intervals (see Figure 4). The number of neurons in the hidden layer is selected based on the common heuristic law, which is equal to two times the number of input layer neurons plus one, resulting in 15 hidden neurons (Stathakis, 2009). Category 1 indicates no sinkhole, while category 10 indicates that the sinkhole size is greater than $24 \mathrm{~m}$. The neural network is constructed by adjusting a number of parameters, including the learning rate, the momentum factor coefficient, the number of training epochs (iterations) and the root mean square error (RMSE). The learning rate is a constant controlling the adjustment of the weights associated with the connections, which was set to 0.02 for this analysis. The momentum factor was used to prevent problems of divergence during research for minimum errors and was used to accelerate convergence. It was selected to be 0.9 . The number of iterations was set to 10,000 , and the RMSE value used for the interrupt of the training phase was set to 0.01 .

\section{Results and Discussion}

The sinkhole hazard model was constructed using the ANN analysis with seven input variables, sinkhole size, and the presence or absence of sinkholes. It was found that about $20 \%$ of sinkhole data have no size information. Sinkhole size data follows a lognormal distribution with parameters $\mu=1.1095$ and $\sigma=1.202$. Then, the Box-Cox transformation was applied in order to improve normality in the sinkhole size dataset and also to reduce the effect of outliers. The Grubb's test was also carried out to identify outlier data prior to ANN modeling. Finally, missing values were imputed by means of the MCMC approach and utilized for ANN modeling. As a result, the average and standard deviation of the sinkhole sizes in ECF are $5.41 \mathrm{~m}$ and $5.38 \mathrm{~m}$, respectively.

The ANN results were presented on the sinkhole hazard map (see Figures 5 and 6). The probability distribution for each location with a $500 \times 500 \mathrm{~m}$ grid is provided throughout the study area. Ten size categories were configured on the output layer, resulting in a total of ten sinkhole hazard maps. For example, the sinkhole hazard map for Category 1 (i.e. no sinkhole) shows the spatial probability distribution that no sinkhole will occur in

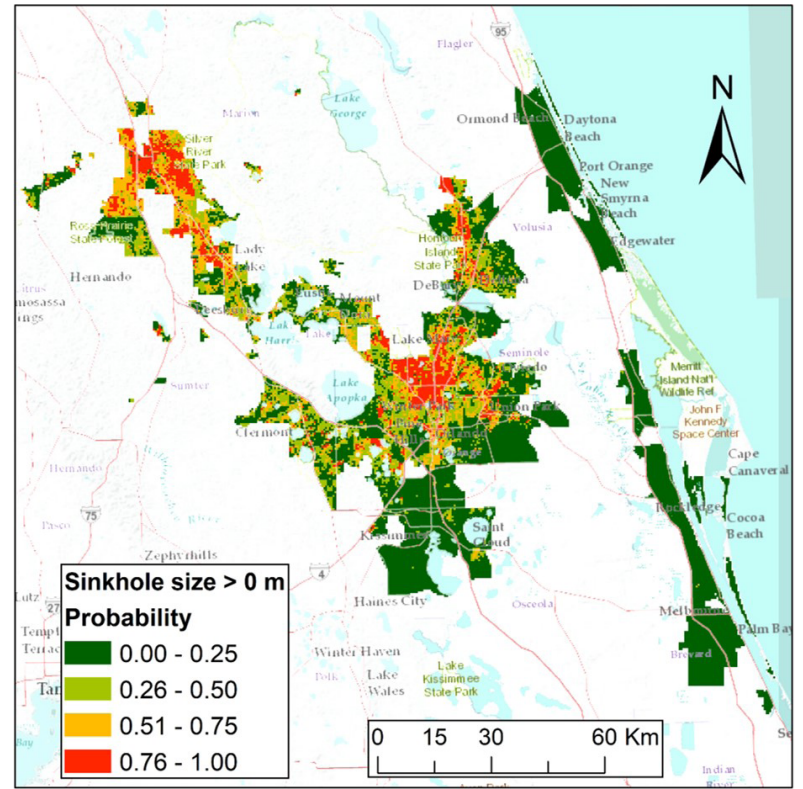

Figure 5. Sinkhole susceptibility map showing the probability of all sizes.

ECF in the future. The Category 2 map represents the probability distribution of sinkholes whose size is greater than $0 \mathrm{~m}$ and less than $3 \mathrm{~m}$. After obtaining the probability distributions of the total ten categories, the probability of sinkhole occurrence with a certain size or more in a specific location was calculated. The probability of sinkhole occurrence greater than $0 \mathrm{~m}$ corresponds to the sum of the probability distributions from Categories 2 through 10; thus, this map represents a typical sinkhole susceptibility map (see Figure 5). It is an important note that the time variable is not considered in the model development, thus the valid time of the model prediction would be similar to the time of sinkhole data collection under similar climate and/or human activities (e.g., urban construction, groundwater pumping for irrigation, etc.). Similarly, the map of Category 10 shows the probability distribution of sinkholes over $24 \mathrm{~m}$. Figure 6 shows four examples of sinkhole hazard maps when the sinkhole size is 0 to $3 \mathrm{~m}$ (Category 2), 3 to $6 \mathrm{~m}$ (Category 3), 6 to $9 \mathrm{~m}$ (Category 4), and greater than $9 \mathrm{~m}$ (Category 5 and up).

The probability of sinkholes larger than $0 \mathrm{~m}$ is widely distributed in both Ocala and Orlando areas, while the probability of sinkholes larger than $3 \mathrm{~m}$ is significantly lower in the Ocala area and somewhat higher in the Orlando area. This is consistent with the fact that sinkholes in the Orlando area are on average larger than sinkholes 


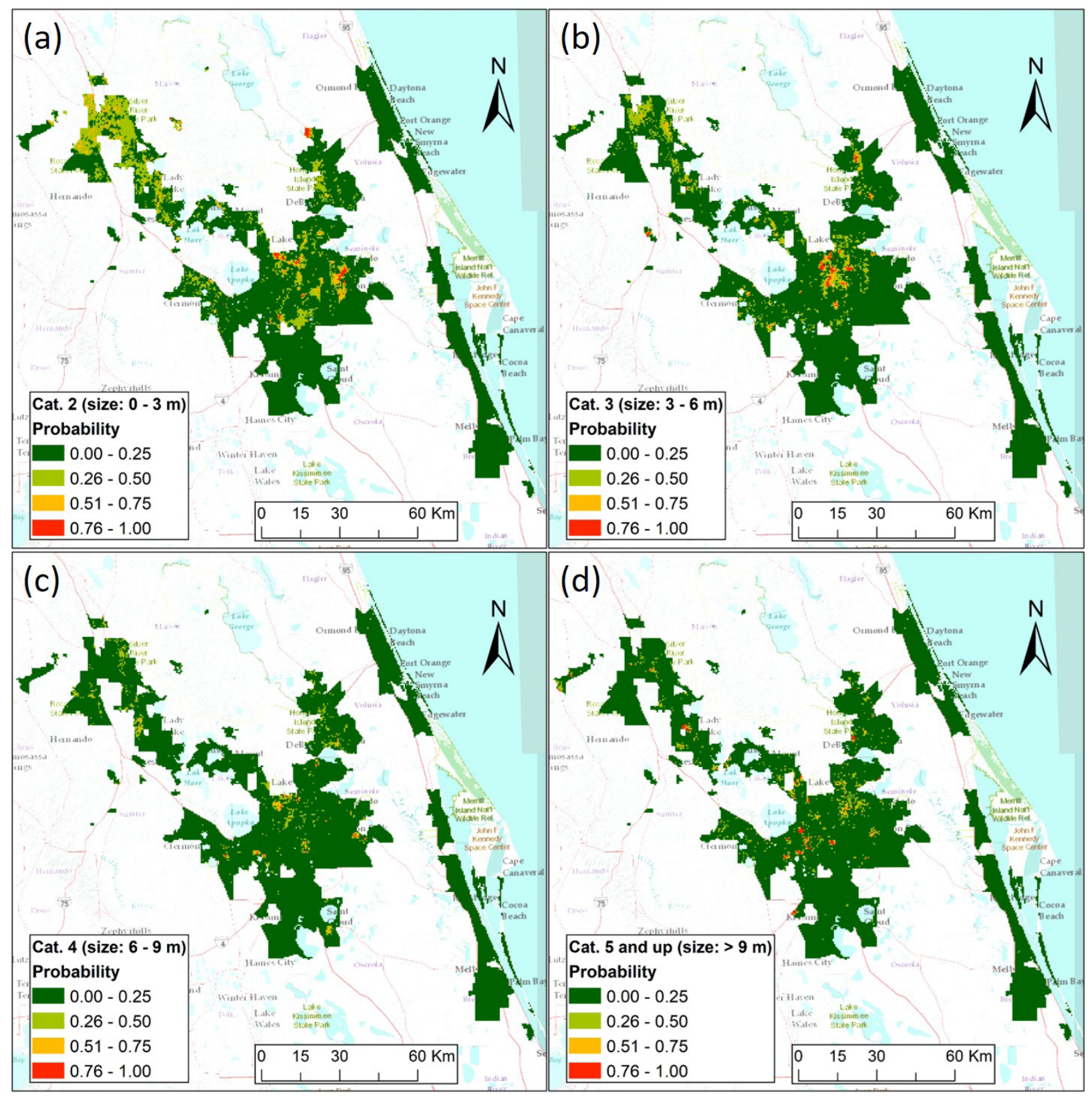

Figure 6. Sinkhole hazard maps of (a) category 2 (size: 0 to $3 \mathrm{~m}$ ), (b) category 3 (size: 3 to $6 \mathrm{~m}$ ), (c) category 4 (size: 6 to $9 \mathrm{~m}$ ), and (d) category 5 and up (size: $>9 \mathrm{~m}$ ).

in the Ocala area. In addition, the probability of sinkholes in some areas of central Florida region larger than $9 \mathrm{~m}$ is quite high, over $76 \%$.

\section{Conclusions}

This paper introduces a methodology to develop the sinkhole location-size prediction model and presents a preliminary result. The study area was limited to ECF where active sinkhole activities are present. Key sinkhole contributing factors were selected and each variable was validated by checking the relationship with the sinkhole frequency. Missing values of sinkhole sizes were imputed using various statistical methods. The ANN method was then applied to develop the probabilistic sinkhole model, and GIS-based mapping was employed. The sinkhole hazard map shows that the northwestern (i.e. Ocala area) and central (i.e. Orlando area) parts of 
ECF are most susceptible to sinkholes. The map also shows that the Orlando area has a higher probability of larger sinkholes than the Ocala area. This result is consistent with the fact that areas with thick overburden layers produce larger sinkholes than thin areas. As future research, time information may be incorporated into the location-size model. This will allow to predict the probability distribution of when, where and how large sinkholes will likely occur in ECF.

\section{References}

Corder GW, Foreman DI. 2009. Nonparametric Statistics for Non-Statisticians: A Step-by-Step Approach. 1st ed., Hoboken, NJ: John Wiley \& Sons, Inc. 247 p.

FDEP. 2019. Florida Subsidence Incident Reports. FDEP, Florida Geological Survey.

Florida Office of Insurance Regulation. 2010. Report on Review of the 2010 Sinkhole Data Call. Florida Office of Insurance Regulation (FOIR), pp. 33.

Gutiérrez F, Guerrero J, Lucha P. 2008. Quantitative sinkhole hazard assessment. A case study from the Ebro Valley evaporite alluvial karst (NE Spain). Natural Hazards 45 (2): 211-233.

Hickey JJ, Vecchioli J. 1986. Subsurface injection of liquid waste with emphasis on injection practices in Florida. Water Supply Paper 2281, U.S. Geological Survey.

Kim Y, Nam BH. 2018. A Comparative Study of Karst Sinkhole Hazard Mapping Using Frequency Ratio and Artificial Neural Network for East Central Florida. Proceedings of the 15th Multidisciplinary Conference on Sinkholes and the Engineering and Environmental Impacts of Karst and the 3rd Appalachian Karst Symposium; Shepherdstown, West Virginia: National Cave and Karst Research Institute. 105-113 p.

Kim YJ, Nam BH. 2017. Sinkhole Hazard Mapping Using Frequency Ratio and Logistic Regression Models for Central Florida. Geo-Risk 2017; Denver, CO: American Society of Civil Engineers. 246-256 p.

Kuniansky EL, Weary DJ, Kaufmann JE. 2016. The current status of mapping karst areas and availability of public sinkhole-risk resources in karst terrains of the United States. Hydrogeology Journal 24 (3): 613-624.

Lee TM, Adams DB, Tihansky AB, Swancar A. 1991. Methods, instrumentation, and preliminary evaluation of data for the hydrologic budget assessment of Lake Lucerne, Polk County, Florida. Water-Resources Investigations Report 90-4111, U.S. Geological Survey.

Lichtler WF. 1972. Appraisal of water resources in the East Central Florida Region. Report of Investigations No. 61, Florida Bureau of Geology, Tallahassee, FL.

Ozdemir A. 2016. Sinkhole susceptibility mapping using logistic regression in Karapınar (Konya, Turkey). Bulletin of Engineering Geology and the Environment 75 (2): 681-707.

Smith MJd. 2018. Statistical Analysis Handbook: A Comprehensive Handbook of Statistical Concepts, Techniques and Software Tools. 2018 ed., Drumlin Security Ltd, Edinburgh: Winchelsea Press. 638 p.

Stathakis D. 2009. How many hidden layers and nodes? International Journal of Remote Sensing 30 (8): 2133-2147.

Subedi P, Subedi K, Thapa B, Subedi P. 2019. Sinkhole susceptibility mapping in Marion County, Florida: Evaluation and comparison between analytical hierarchy process and logistic regression based approaches. Scientific Reports 9 (1): 7140.

Tibbals CH. 1990. Hydrology of the Floridan aquifer system in east-central Florida. 1403-E, U.S. Geological Survey, Professional Paper 1403-E.

Tihansky AB, Knochenmus LA. 2001. Karst Features and Hydrogeology in West-central Florida -A Field Perspective. in: Kuniansky EL (Ed.), U.S. Geological Survey Karst Interest Group Proceedings. U.S. Geological Survey, WaterResources Investigations Report 01-4011, pp. 198-211.

Upchurch S, Scott TM, Alfieri MC, Fratesi B, Dobecki TL. 2019. The Karst Systems of Florida: Understanding Karst in a Geologically Young Terrain. Cham, Switzerland: Springer. 459 p. 
Weary DJ. 2015. The Cost of Karst Subsidence and Sinkhole Collapse in the United States Compared with Other Natural Hazards. Proceedings of the 14th Multidisciplinary Conference on Sinkholes and the Engineering and Environmental Impacts of Karst; Rochester, MN: National Cave and Karst Research Institute. 433-446 p.

Wu J et al. 2019. Hyperparameter Optimization for Machine Learning Models Based on Bayesian Optimization. Journal of Electronic Science and Technology 17 (1): 26-40.

Zhou G, Yan H, Chen K, Zhang R. 2016. Spatial analysis for susceptibility of second-time karst sinkholes: A case study of Jili Village in Guangxi, China. Computers \& Geosciences 89 144-160.

Zou J, Han Y, So S-S. 2009. Overview of Artificial Neural Networks. in: Livingstone DJ (Ed.), Artificial Neural Networks: Methods and Applications. Humana Press, Totowa, NJ, pp. 14-22. 